Supporting information for:

\title{
Epitaxial-strain-induced spontaneous magnetization in polar $\mathrm{Mn}_{2} \mathrm{Mo}_{3} \mathrm{O}_{8}$
}

Shishin $\mathrm{Mo}^{1}$, Tsukasa Katayama ${ }^{2 *}$, Akira Chikamatsu ${ }^{1}$, Miho Kitamura ${ }^{3}$, Koji Horiba ${ }^{4}$, Hiroshi Kumigashira $^{5}$ and Tetsuya Hasegawa ${ }^{1}$

${ }^{1}$ Department of Chemistry, The University of Tokyo, Bunkyo-ku, Tokyo, 113-0033, Japan

${ }^{2}$ Research Institute for Electronic Science, Hokkaido University, Sapporo, Hokkaido, 001-0020, Japan

${ }^{3}$ Institute of Materials Structure Science, High Energy Accelerator Research Organization (KEK), 11 Oho, Tsukuba, Ibaraki, 305-0801, Japan

${ }^{4}$ National Institutes for Quantum and Radiological Science and Technology (QST), 1-1-1 Kouto, Sayo-cho, Sayo-gun, Hyogo, 679-5148, Japan

${ }^{5}$ Institute of Multidisciplinary Research for Advanced Materials, Tohoku University, 2-1-1 Katahira, Aoba-ku, Sendai, Miyagi, 980-8577, Japan 


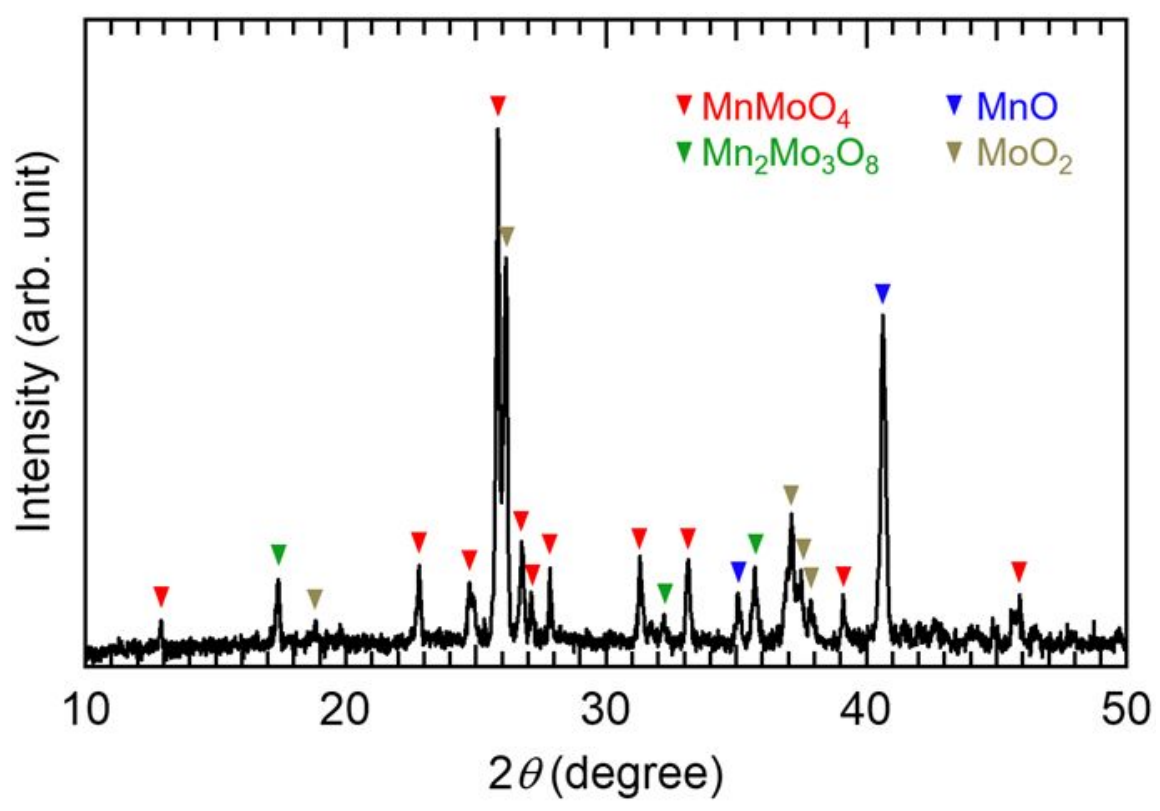

Figure S1. $2 \theta-\theta$ XRD pattern of the PLD target.

Figure S1 shows the $2 \theta-\theta$ XRD pattern of the prepared PLD target, showing the presence of four crystal phases in the target: $\mathrm{Mn}^{2+} \mathrm{O}, \mathrm{Mo}^{4+} \mathrm{O}_{2}, \mathrm{Mn}^{2+} \mathrm{Mo}^{6+} \mathrm{O}_{4}$, and $\mathrm{Mn}^{2+}{ }_{2} \mathrm{Mo}^{4+}{ }_{3} \mathrm{O}_{8} \cdot{ }^{1-4}$ Therefore, the Mo valence state of the PLD target was higher than that of $\mathrm{Mn}_{2} \mathrm{Mo}_{3} \mathrm{O}_{8}$, while the $\mathrm{Mn}$ valence states were the same. 

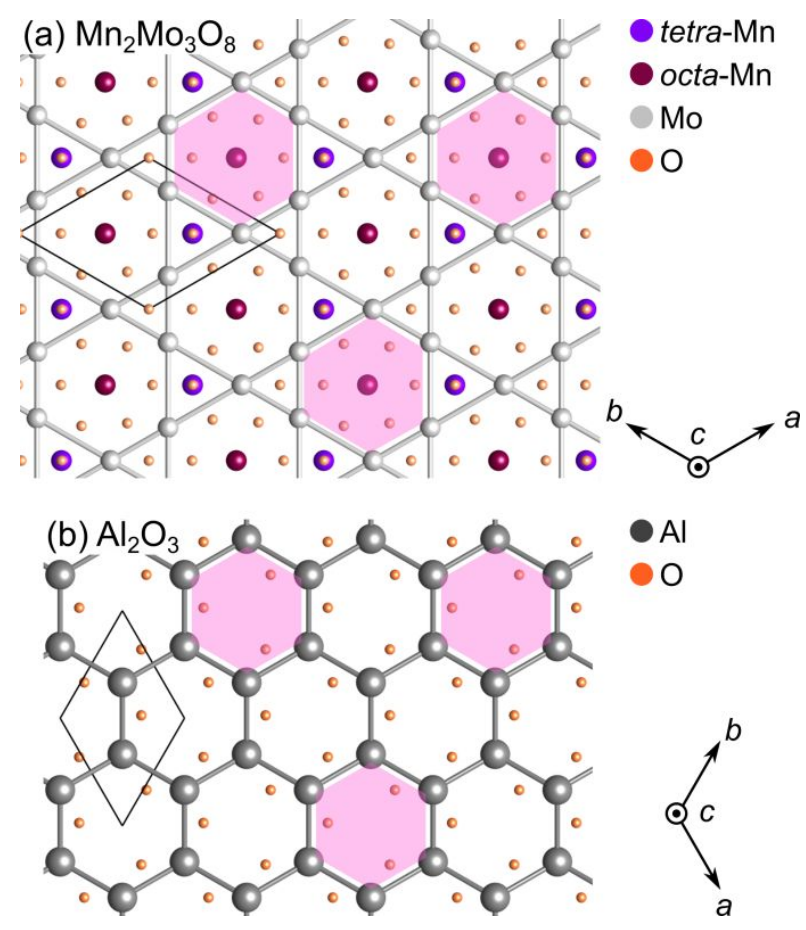

Figure S2. Top-view ionic arrangements of the crystal structures of (a) $\mathrm{Mn}_{2} \mathrm{Mo}_{3} \mathrm{O}_{8}$ and (b) $\mathrm{Al}_{2} \mathrm{O}_{3}$.

Pink hexagons in Figs. (a) and (b) show $\mathrm{Mo}_{6}$ hexagons and $\mathrm{Al}_{6}$ hexagons, respectively.

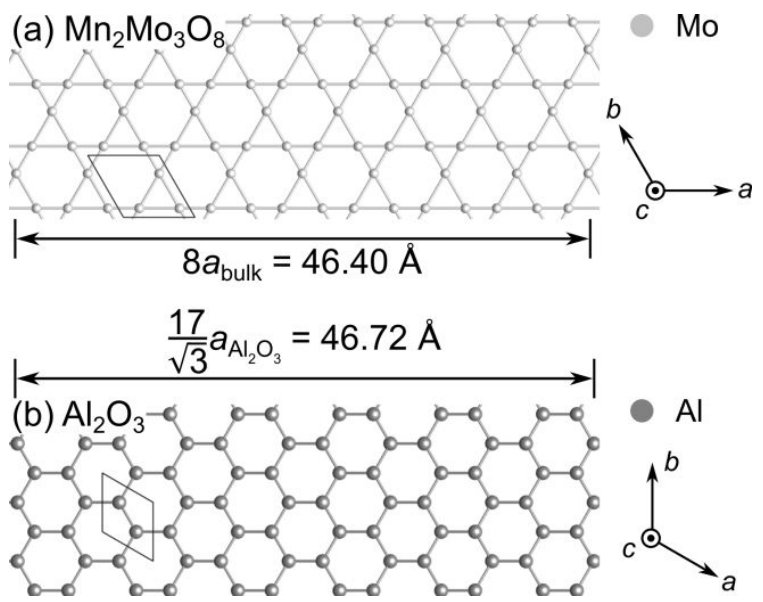

Figure S3. Top-view cationic arrangements of the crystal structures of (a) $\mathrm{Mn}_{2} \mathrm{Mo}_{3} \mathrm{O}_{8}$ film (Mn ions are omitted for clarity) and (d) $\mathrm{Al}_{2} \mathrm{O}_{3}$ substrate. 


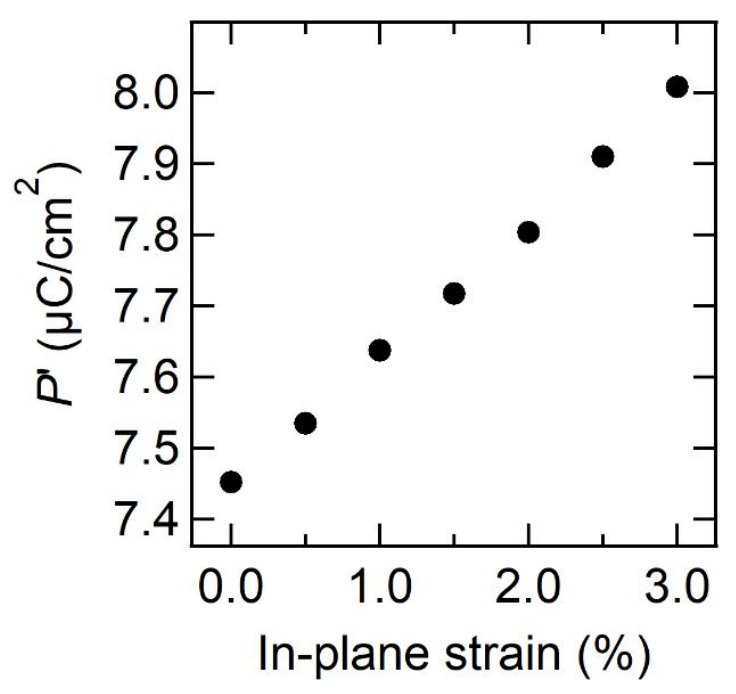

Figure S4. DFT-calculated $P^{\prime}$ values of $\mathrm{Mn}_{2} \mathrm{Mo}_{3} \mathrm{O}_{8}$ as a function of in-plane strain.

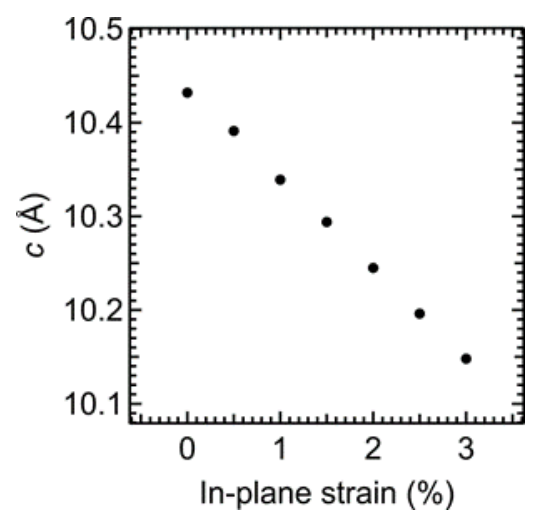

Figure S5. Calculated $c$-axis lengths of $\mathrm{Mn}_{2} \mathrm{Mo}_{3} \mathrm{O}_{8}$ as a function of in-plane tensile strain.

\section{Reference}

(1) Qiu, T.; Wang, J.; Lu, Y.; Yang, W. Facile Fabrication of Chinese Lantern-like MnO@N-C: A High-Performance Anode Material for Lithium-Ion Batteries. RSC Adv. 2014, 4, 23027-23035.

(2) Musil, M.; Choi, B.; Tsutsumi, A. Morphology and Electrochemical Properties of $\alpha-, \beta$-, $\gamma$-, and $\delta-\mathrm{MnO}_{2}$ Synthesized by Redox Method. J. Electrochem. Soc. 2015, 162, A2058-A2065.

(3) Dutta, D. P.; Mathur, A.; Ramkumar, J.; Tyagi, A. K. Sorption of Dyes and Cu(II) Ions from Wastewater by Sonochemically Synthesized $\mathrm{MnWO}_{4}$ and $\mathrm{MnMoO}_{4}$ Nanostructures. RSC Adv. 2014, 4, 37027-37035.

(4) Abe, H.; Sato, A.; Tsujii, N.; Furubayashi, T.; Shimoda, M. Structural Refinement of $T_{2} \mathrm{Mo}_{3} \mathrm{O}_{8}$ $(T=\mathrm{Mg}, \mathrm{Co}, \mathrm{Zn}$ and $\mathrm{Mn}$ ) and Anomalous Valence of Trinuclear Molybdenum Clusters in $\mathrm{Mn}_{2} \mathrm{Mo}_{3} \mathrm{O}_{8}$. J. Solid State Chem. 2010, 183, 379-384. 